\title{
Inorganic-organic Hybrids Originating from Organosilane Anchored Onto Leached Vermiculite
}

\author{
Ana P. M. Alves ${ }^{\mathrm{a} *}$, Maria G. Fonseca ${ }^{\mathrm{b}}$, Albaneide Fernandes Wanderley \\ ${ }^{a}$ Departamento de Química, Universidade Federal do Rio Grande do Norte - UFRN, \\ CEP 59072-970, Natal, RN, Brazil \\ ${ }^{\mathrm{b}}$ Departamento de Química, CCEN, Universidade Federal da Paraíba - UFPB, \\ CEP 58059-900, João Pessoa, PB, Brazil \\ 'Universidade Federal Rural de Pernambuco - UFRPE, Serra Talhada, PE, Brazil
}

Received: June 19, 2012; Revised: January 14, 2013

\begin{abstract}
The reactivity of clay minerals leached in grafting reactions was investigated. Precursor solids were prepared by treating the sodium vermiculites with nitric acid solutions at several concentrations. The lixiviation produced the restructured porous solids with surface area over a wide range, varying from 133 to $673 \mathrm{~m}^{2} \mathrm{~g}^{-1}$. The sodium and lixiviated vermiculites reacted covalently with silylating agent, 3-aminopropyltrimethoxysilane, to attach this agent onto the inorganic surface, through the free available silanols. The products were characterized by $\mathrm{CNH}$ elemental analysis, infrared spectroscopy, $\mathrm{X}$-ray diffraction, nuclear magnetic resonance in the solid state for carbon and silicon. CHN data expressed by significant contents of anchored organic chains, up to $2.14 \mathrm{mmol} \mathrm{g}^{-1}$, as the degree of leaching was increased. The success of this investigation is directly related to the leaching of the natural vermiculite, which is strongly influenced by the reactivity of the abundant original source.
\end{abstract}

Keywords: vermiculite, organoclays, selective leaching, silylation

\section{Introduction}

The properties associated with some inorganic solids having organic guest molecules incorporated on the established inorganic layer through immobilization processes leads to new organofunctionalized compounds, which have attracted great attention from both scientific and practical viewpoints ${ }^{1-4}$. In this context, the grafting involves organosilanes that enable covalent bond formations with available reactive surface groups. For example, a natural clay mineral, when reacted with a suitable organic species, yields a product with increased hydrophobization of the surface particles. Thus, the $2: 1$ clay minerals provide either silanol and aluminol groups on their surfaces, whose structural availability offer favorable condition to attach desirable pendant chains onto the inorganic framework, from the organosilane grafting process ${ }^{5}$. Following the grafting model reaction ${ }^{6}$, the original hydrophilic surface becomes organophilic, as is proposed for clay sepiolite dispersed in low-polarity solvents, including also some polymers. Another feature is related to layered leached clays in the presence of specific reactive molecules like silanes, where new organofunctionalized materials are directly produced ${ }^{7,8}$.

Based on the advantage in using natural minerals, the chemically modified clay surface has received great attention not only due to the new synthetic materials, but also due to their expressive applications. Thus, organoclays are essential in developing polymer nanocomposites, that constitutes one of the most developed areas of nanotechnology $y^{9,10}$, mainly when the investigation is focused on the organofunctionalization of

*E-mail: anachemistry@ hotmail.com lixiviated vermiculite. Selective leaching of minerals from clay treated with acid is a simple procedure for preparing porous silica. In such cases, all the components except silica are almost completely leached by strong acid and/or long maintenance at slightly higher temperatures ${ }^{11}$. The resulting operation from leaching can yield favorable components that introduce pores in the final products. In case of porous silica this has proven useful as pollutants adsorbents ${ }^{12-15}$, catalyst supports ${ }^{16-18}$ and cracking catalysts ${ }^{19}$.

One of the most explored native clay material is vermiculite that can be naturally found as a 2:1 composition and its importance is reflected in many commercial applications $s^{20,21}$. From the structural viewpoint, natural vermiculites possess characteristic substitutions in octahedral and tetrahedral layers which could affect the properties of the final compositions, after acidic treatment. Thus, this operation needs caution to optimize the manipulation as a function of the desired application of the material obtained.

Smectites and vermiculites contain low concentrations of silanol groups due to the fact that they occur only at particle edges. Acid-treated vermiculite produces specific sites at the layer edges, where unsaturated "broken" bonds occur, which may be compensated by $\mathrm{OH}$ group formation, leading to Brønsted acidic sites like $\mathrm{Si}-\mathrm{OH}^{22}$. These newly formed silanol groups, located on the external surface, at the structural channel edges, become directly accessible to the reagents, mainly when the interest is directed to chemical surface modification and the special focus is the use of silylating agent. 
The present investigation involves grafting active clay materials with 3-aminopropyltriethoxysilane. The resulting products were characterized through infrared spectroscopy, $\mathrm{X}$-ray diffraction patterns and nuclear magnetic resonance in the solid state for silicon and carbon. The aim of this study is to elucidate the effect of silylation within the interlayer microstructure of the grafted clay material, which is a proposed strategic step for a general synthetic procedure for valuable chemical modification of polymer/layered silicate nanocomposites.

\section{Experimental Procedures}

\subsection{Starting material}

The vermiculite sample was supplied by the União Brasileira de Mineração from Santa Luzia, state of Paraiba, Brazil. The chemical composition of raw vermiculite in mass percentage was: $\mathrm{SiO}_{2}$ (44.62); $\mathrm{Al}_{2} \mathrm{O}_{3}(9.18) \mathrm{Fe}_{2} \mathrm{O}_{3}$ (5.46); $\mathrm{CaO}$ (0.78); $\mathrm{MgO}$ (20.44); $\mathrm{Na}_{2} \mathrm{O}(0.11) ; \mathrm{K}_{2} \mathrm{O}(0.48)$ and fire loss (18.93).

\subsection{Selective leaching}

Nitric acid aqueous solutions with concentrations 1.0, 2.0, 3.0 and $4.0 \mathrm{~mol} \mathrm{dm}^{-3}$ were used as leaching agent. In a typical procedure, a sample of raw vermiculite $(50 \mathrm{~g})$ was suspended in $500.0 \mathrm{~cm}^{3}$ of acid solution for $4 \mathrm{~h}$ at $363 \mathrm{~K}$. Next, $100.0 \mathrm{~cm}^{3}$ of cold distilled water was added and the sample allowed to cool for 30 minutes. The suspension was filtered and dried at $383 \mathrm{~K}$ overnight. The samples were named $\mathrm{Vm}$, where $\mathrm{m}=1$ to 4 , corresponding to the sequence of the aqueous acid concentrations used.

\subsection{Synthesis of chemically modified clay}

Each functionalized solid was synthesized following a procedure described previously ${ }^{23}$. Briefly, a vermiculite sample of $3.0 \mathrm{~g}$ was initially heated at $373 \pm 1 \mathrm{~K}$ under vacuum for 24 hours, to moisture removal. Then the activated clay was suspended in $150.0 \mathrm{~cm}^{3}$ of dry toluene in a three-neck flask, to which $5.0 \mathrm{~cm}^{3}(14.32 \mathrm{mmol})$ of the silylating agent, 3-aminopropyltrimethoxysilane (APS) (Aldrich) was added, under a dry nitrogen flow and the reaction was performed under solvent reflux for $72 \mathrm{~h}$. The solid obtained was separated by filtration and washed first with toluene, followed by ethanol and water. Any residual silane was removed by a 24 hours Soxhlet ethanol extraction, to yield a solid named Vm-N.

\subsection{Characterizations}

The amount of organic groups immobilized onto the vermiculite surface was calculated based on the percentages of carbon, hydrogen and nitrogen determined by elemental analysis on a Perkin-Elmer, model 2400, instrument.

The sodium and chemically modified vermiculites were characterized using X-ray diffraction patterns with nickel-filtered $\mathrm{Cu} K \alpha$ radiation on a Shimadzu Model XD3A diffractometry equipment in the range $2 \theta=1.5-70^{\circ}$ and at a scan rate of $0.67^{\circ} \mathrm{s}^{-1}$. FTIR spectra measurements were done on a Bomen MB series spectrophotometer using $\mathrm{KBr}$ pellets. The spectra were collected 32 times in the $4000-400 \mathrm{~cm}^{-1}$ range at a resolution of $4 \mathrm{~cm}^{-1}$. NMR spectra were obtained on a Bruker AC 300/P spectrometer at room temperature. For each run, approximately one gram of the solid sample was compacted into a $7 \mathrm{~mm}$ zirconium oxide rotor. The ${ }^{29} \mathrm{Si}$ spectra were acquired using a $90^{\circ}$ pulse of $60 \mu$ s and recycle time of $100 \mathrm{~s}$, and were referenced to tetramethylsilane (TMS). $\mathrm{C}^{13}$ spectra were obtained at frequencies of $75.47 \mathrm{MHz}$ and magic angle spinning (MAS) of $4 \mathrm{kHz}$. To increase the signal to noise ratio of the spectra, the cross-polarization (CP) technique was also applied. The ${ }^{13} \mathrm{C}$ spectra were obtained with pulse repetitions of $1 \mathrm{~s}$ and contact times of $1 \mathrm{~ms}$. The chemical composition were determined in clay digestates by inductively coupled plasma optical emission spectrometry. TG measurements were carried on heating under nitrogen flowing $50 \mathrm{ml} . \mathrm{min}^{-1}$ by using a thermobalance DTG-60H - Shimadzu model Simultaneous Apparatus DTA-TG, in a temperature range $303-1173{ }^{\circ} \mathrm{C}$ at heating rate of $5^{\circ} \mathrm{K} \cdot \mathrm{min}^{-1}$.

A JSM-6701F field-emission scanning electron microscope (FE-SEM) (JEOL) was used to investigate the morphology of each sample before and after silylation. The specific surface areas were measured with an Accelerated Surface Area and Porosimetry System (Micromeritics, ASAP 2020) by BET-method through nitrogen adsorption at $76 \mathrm{~K}$.

\section{Results and Discussion}

\subsection{Precursor solids}

\subsubsection{Chemical composition}

Chemical analysis of the main components and the specific surface area $\left(\mathrm{S}_{\mathrm{BET}}\right)$ of the as-received and leached solids are listed in Table 1. The leached samples showed

Table 1. Chemical composition and specific surface area $\left(\mathrm{S}_{\mathrm{BET}}\right)$ change of the raw and leached samples.

\begin{tabular}{|c|c|c|c|c|c|c|c|}
\hline \multirow{2}{*}{ Sample } & \multirow{2}{*}{$\begin{array}{c}\mathrm{S}_{\mathrm{BET}} \\
\left(\mathrm{m}^{2} \mathrm{~g}^{-1}\right)\end{array}$} & \multicolumn{6}{|c|}{ Chemical composition (\%) } \\
\hline & & $\mathrm{SiO}_{2}$ & $\mathrm{Al}_{2} \mathrm{O}_{3}$ & $\mathrm{Fe}_{2} \mathrm{O}_{3}$ & MgO & $\mathrm{H}_{2} \mathrm{O}^{*}$ & Others components \\
\hline $\mathrm{V}$ & 16 & 44.62 & 9.18 & 5.46 & 20.64 & 11.8 & 8.30 \\
\hline V1 & 133 & 47.60 & 7.54 & 5.29 & 13.82 & 12.2 & 13.55 \\
\hline $\mathrm{V} 2$ & 339 & 55.80 & 5.01 & 4.04 & 6.94 & 17.2 & 11.01 \\
\hline V3 & 673 & 58.80 & 0.88 & 1.37 & 0.95 & 23.7 & 14.30 \\
\hline V4 & 575 & 61.30 & 0.62 & 0.79 & 0.92 & 23.8 & 12.57 \\
\hline
\end{tabular}

*obtained by thermogravimetry. 
important alterations when compared to the precursor vermiculite, especially those derived from acid treatment at higher concentrations. Silica content significant increased after treatment with 3.0 and $4.0 \mathrm{~mol} \mathrm{dm}^{-3}$ of nitric acid, which can be attributed to the dissolution of the other inorganic components. The increase in specific surface area $\left(\mathrm{S}_{\mathrm{BET}}\right)$ of the leached products was directly related to the acid concentration. A maximum $\mathrm{S}_{\mathrm{BET}}$ value of $673 \mathrm{~m}^{2} \mathrm{~g}^{-1}$ was obtained with $3.0 \mathrm{~mol} \mathrm{dm}^{-3}$, which is the highest reported result for porous materials, when synthesized from mineral clays by selective leaching ${ }^{24}$. Temujin et al. ${ }^{24}$ have studied the preparation of porous silica vermiculite by selective leaching, noting that the micropores partially collapsed as a result of these structural changes, which explains the decrease of $\mathrm{S}_{\mathrm{BET}}$ when the material is subjected to an intense acid treatment, similar behavior the sample V4 $\left(\mathrm{S}_{\mathrm{BET}}=575 \mathrm{~m}^{2} \mathrm{~g}^{-1}\right)$.

XRD demonstrated some changes in the final solid crystalline structure after lixiviation with longer reaction time indicating a decrease in the intensity of the basal reflection (002) and other reflections attributed to (020), (110), (021) and (060) plans, as shown in Figure 1. The decrease in crystallinity transforms the solid to an amorphous form, which was observed from the acidic concentration of $3.0 \mathrm{~mol} \mathrm{dm}^{-3}$, as shown for $\mathrm{V} 3$ sample.

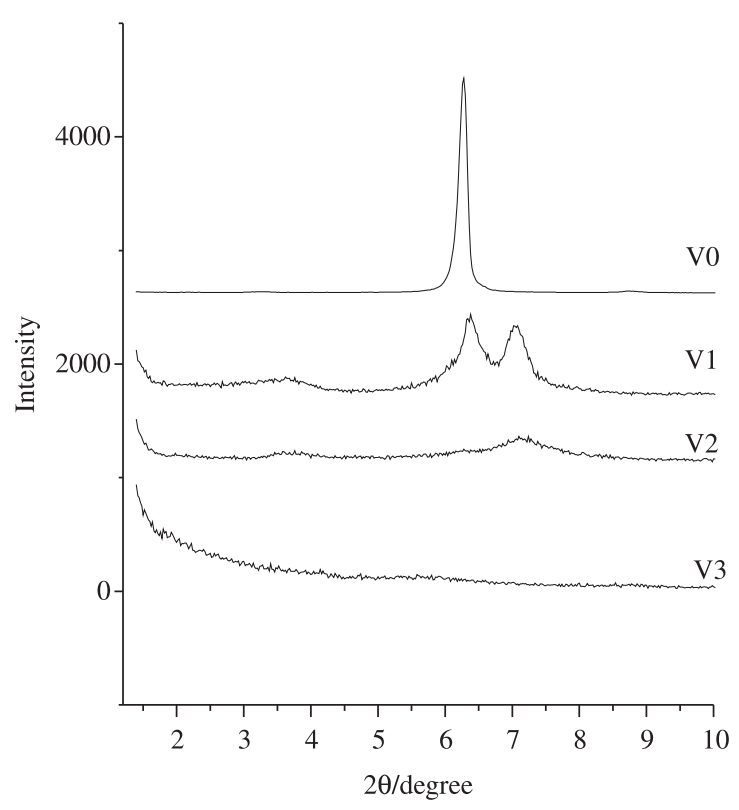

Figure 1. XRD patterns of raw and $\operatorname{Vm}(m=1,2,3)$ series products.
This behavior is attributed to the increased amount of metals leached from the inorganic structure as well as the possible lamellar exfoliation, which accounts for the decreased intensity of the peak indexed as $(002)^{5}$.

\subsection{Hybrids}

The CNH contents resulting from elemental analyses are listed in Table 2, including also the degree of functionalization as well, and the density of the pendant organic molecules $\left(d_{f}\right)$ attached to the host matrices, which was calculated from the nitrogen content. The increased density of the pendant groups for V3-N was expected due to the high surface area, a structure that favors the immobilization on this clay. Also the $\mathrm{C} / \mathrm{N}$ ratios for all anchored compounds suggested that the organic chains, covalently bonded to the inorganic layers, did not alter as the immobilizations took place.

The derivatives originating from leached vermiculite demonstrated a significant increase in the anchored organic groups, reaching $2.14 \mathrm{mmol} \mathrm{g}^{-1}$ for $\mathrm{V} 3-\mathrm{N}$, while the as-received clay showed a reduced value of $0.64 \mathrm{mmol} \mathrm{g}^{-1}$. This is due to the new silanol groups formed, and the highest surface area of $673 \mathrm{~m}^{2} \mathrm{~g}^{-1}$ for V3, against $16 \mathrm{~m}^{2} \mathrm{~g}^{-1}$ for the original clay. This result clearly indicates that the leaching treatment strongly influenced on the reactivity of the original vermiculite.

The infrared spectra of the precursor vermiculite $\mathrm{V}-\mathrm{N}$ and those organofunctionalized V1-N, V2-N, and V3-N are shown in Figure 2. A broad band at $3500 \mathrm{~cm}^{-1}$ was attributed to $\mathrm{OH}$ stretching vibration from sorbed water and available silanol groups structurally bonded to the surface. Weak asymmetric and symmetric $\mathrm{v}(\mathrm{C}-\mathrm{H})$ bands are assigned to the frequencies at 2935 and $2870 \mathrm{~cm}^{-1}$. This band corresponds to the $\mathrm{CH}_{2}$ stretching mode of APS, in agreement with the presence of silane in the grafted products. The sharp and intense bands observed at 1035 and $1110 \mathrm{~cm}^{-1}$ are assigned to the Si-O-Si stretching backbone bonds of the siloxane group. The other band also around $1650 \mathrm{~cm}^{-1}$, is attributed to the angular vibration of the water molecules bonded to the inorganic structural backbone. Another set of absorption bands were assigned for $[\mathrm{v}(\mathrm{N}-\mathrm{H})]$ at $1540 \mathrm{~cm}^{-1[25]}$.

The XRD patterns of the clay materials before and after grafting are shown in Figure 3. The basal spacings for V, $\mathrm{V} 1$ and $\mathrm{V} 2$ were $1.41,1.38$ and $1.25 \mathrm{~nm}$, respectively, in agreement with the typical pattern of the vermiculite ${ }^{26}$. On the other hand, this basal distance decreased to $1.38 \mathrm{~nm}$, as the clay was organofunctionalized. The main change in the $\mathrm{X}$-ray diffraction patterns after grafting reaction was the basal spacing, showing the new values of $1.38,1.37$ and

Table 2. Percentages of carbon $(\mathrm{C})$ and nitrogen $(\mathrm{N})$, the respective density of pendant organic molecules $(\mathrm{df})$, the molar ratio $(\mathrm{C} / \mathrm{N})$ experimental and the molar ration $\mathrm{C} / \mathrm{N}$ theoretical (teo).

\begin{tabular}{cccccc}
\hline sample & $\mathbf{C} / \boldsymbol{\%}$ & $\mathbf{H} / \boldsymbol{\%}$ & $\mathbf{N} / \boldsymbol{\%}$ & $\mathbf{d f} / \mathbf{~ m m o l ~ g}^{-1}$ & $\mathbf{C} / \mathbf{N}(\mathbf{t e o})$ \\
\hline V-N & $2.29 \pm 0.01$ & $2.13 \pm 0.11$ & $0.89 \pm 0.03$ & $0.64 \pm 0.05$ & $3.00(3.00)$ \\
V1-N & $3.19 \pm 0.03$ & $2.32 \pm 0.08$ & $1.17 \pm 0.04$ & $0.84 \pm 0.03$ & $3.16(3.00)$ \\
V2-N & $4.96 \pm 0.07$ & $2.01 \pm 0.13$ & $1.67 \pm 0.06$ & $1.19 \pm 0.13$ & $3.47(3.00)$ \\
V3-N & $7.95 \pm 0.06$ & $2.14 \pm 0.15$ & $2.99 \pm 0.05$ & $2.14 \pm 0.04$ & $3.10(3.00)$ \\
V4-N & $5.36 \pm 0.08$ & $1.74 \pm 0.09$ & $1.94 \pm 0.09$ & $1.39 \pm 0.07$ & $3.20(3.00)$ \\
\hline
\end{tabular}


$3.12 \mathrm{~nm}$ for V-N, V1-N and V2-N, respectively, as illustrated in Figure $3 b$ and $3 c$.

As expected, clays with different degrees of leached reflect varying $\mathrm{X}$-ray diffraction patterns, that come under two main categories: i) the heterogeneity of the solids, as evident in the XRD suggesting that probably part of the original vermiculite remains inactivated and ii) during the course of immobilization, as the amount of organic molecules incorporated into the inorganic network increased, the possibility of these molecules to be accommodated into the inorganic structure also increased, due to the interaction of the amino groups with the $\mathrm{Si}-\mathrm{OH}$, as demonstrated in Figure 4.

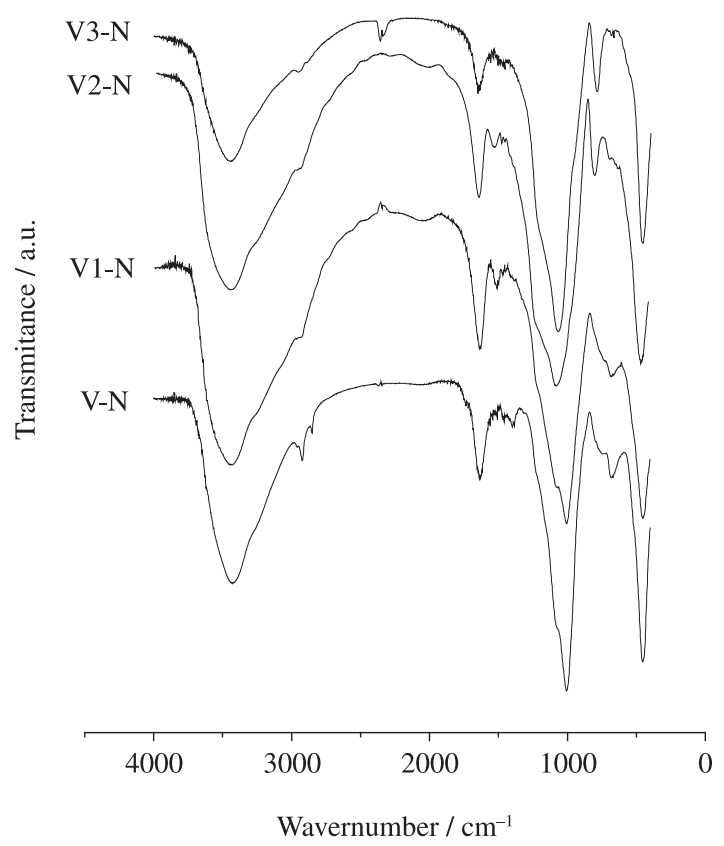

Figure 2. Infrared spectra of the precursor and $\mathrm{Vm}-\mathrm{N}(\mathrm{m}=1,2,3)$ series products.
The synthetic route is in agreement with the fact that preferentially the immobilization process can occur inside of the interlamellar cavity space. Thus, the interlamellar contraction for V-N and V1-N solids is a result of the displacement of the hydrated cations originally sited in this free cavity, as the silylating agent was bonded inside the same space, as observed when a series of n-aliphatic amines were intercalated into these types of inorganic materials ${ }^{27}$. For V-N clay, the silylating chain arrangement was in a monolayer and the condensation between the silane molecules easily takes place, as observed earlier ${ }^{28}$, with a distribution in the parallel monolayer, as the organic molecules or cations within the gallery are individually separated to lower the energy of the hybrid (Figure 4c). Accordingly, there is little possibility for condensation between the silane molecules for parallel monolayer.

For V2-N solids, as shown in Figure 4b, an increase in the interlayer distance suggests that a considerable number of molecules are perpendicularly accommodated inside the interlayer cavity. The non-expansion interlayer detected for $\mathrm{V}$ and V1 is due to the larger silicon and aluminum substitution in the inorganic structure that confers a higher lamellar charge, which makes clay lamellar expansion difficult ${ }^{29}$. However, the leached favors the displacement of metals from the inorganic structure, increasing the $\mathrm{Si} / \mathrm{Al}$ ratio and decreasing the lamellar charge. This makes easily the V2 solid expansion during the reaction due to the molecular entry into this interlamellar region.

The present study demonstrates that the intercalation of silane first occurs during the grafting reaction and the arrangement of the intercalated silane strongly depends on the properties of the layered silicates.

NMR in the solid state provides valuable information on the bonding of the pendant chains incorporated on the inorganic polymer. This technique is useful for proposing structures as well as for drawing conclusions on the bonding between the agents and the surface. The $\mathrm{Si}^{29} \mathrm{NMR}$ spectra for organo vermiculites are shown in Figure 5a. Following the grafting, two additional ${ }^{29} \mathrm{Si}$ signals at -59.8 and

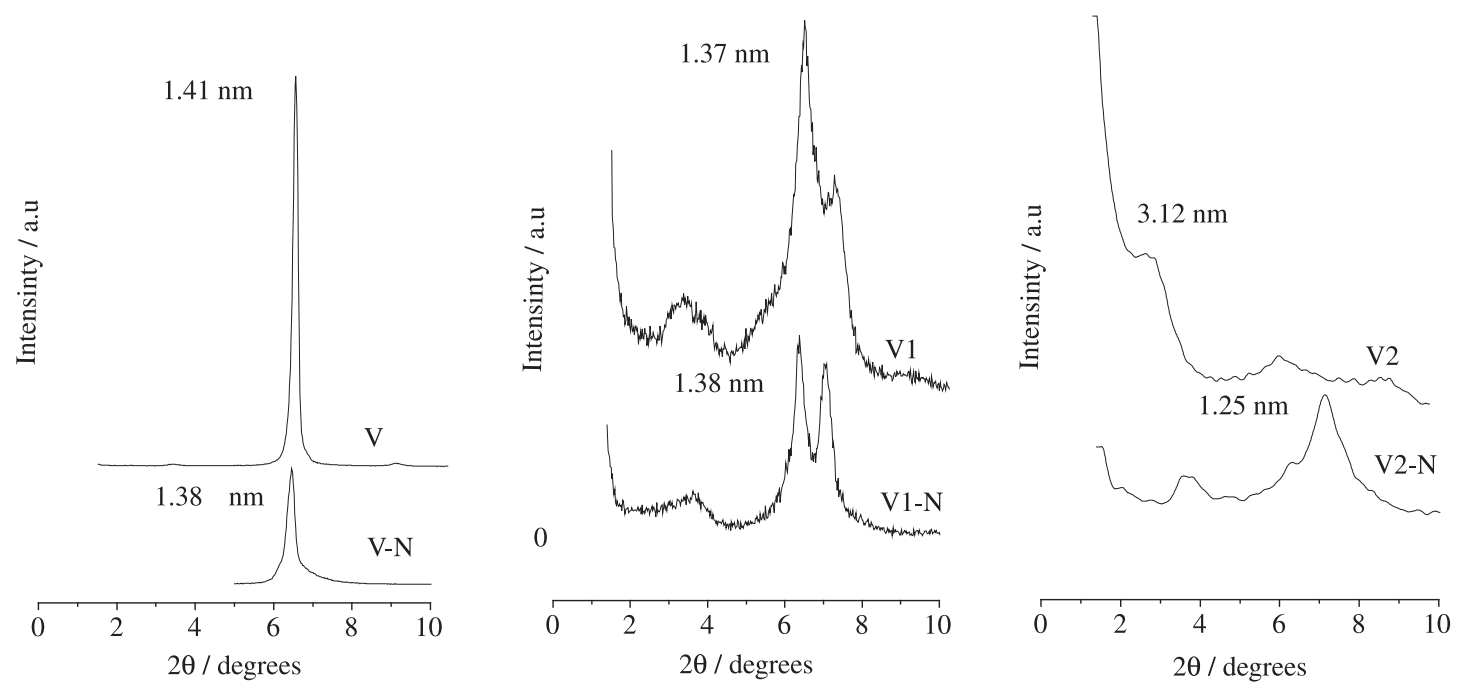

Figure 3. XRD patterns of the host matrices V and V-N, V1, V1-N, V2 and V2-N synthesized organoclays. 
-66.7 ppm were recorded for all hybrids, besides the possible signals for $\mathrm{Q}^{3}$ and $\mathrm{Q}^{4[30]}$. These signals correspond to $\mathrm{T}^{2}$ $\left.\left[\mathrm{Si}(\mathrm{OSi})_{2}(\mathrm{OR})^{\prime}\right) \mathrm{R}\right]\left(\mathrm{R}=\mathrm{CH}_{2} \mathrm{CH}_{2} \mathrm{CH}_{2} \mathrm{NH}_{2}, \mathrm{R}^{\prime}=\mathrm{H}\right.$ or $\left.\mathrm{CH}_{2} \mathrm{CH}_{3}\right)$ and $\mathrm{T}^{3}\left[\mathrm{Si}(\mathrm{OSi})_{3} \mathrm{R}\right]$ units, respectively ${ }^{31,32}$. The signal with a high intensity corresponding to the $\mathrm{T}^{3}$ unit suggests that most silane molecules are covalently bonded to the inorganic structure through tridentate bonds. This conclusion supports the present proposal on the silane arrangement within the gallery based on the XRD patterns. Also, the coexistence of $\mathrm{T}^{2}$ and $\mathrm{T}^{3}$ units provides a clear explanation of the obviously broadened (002) reflection of the hybrids. The ${ }^{13} \mathrm{C}$ NMR spectra reinforced the maintenance of the organic chain structure under reaction conditions for all products through the typical peaks at 43,25 and $10 \mathrm{ppm}$ attributed to propyl spacer chain ${ }^{33,34}$, as shown in Figure 5 b. The proposed conformations for the bonded chains are given in the inserted

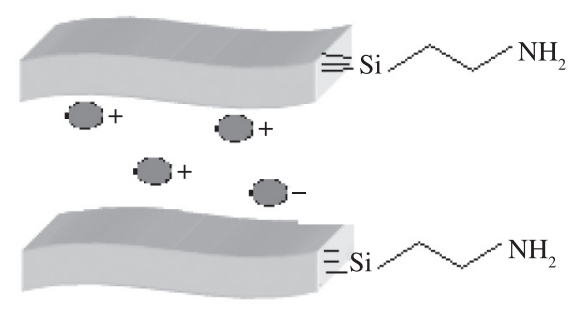

(a)

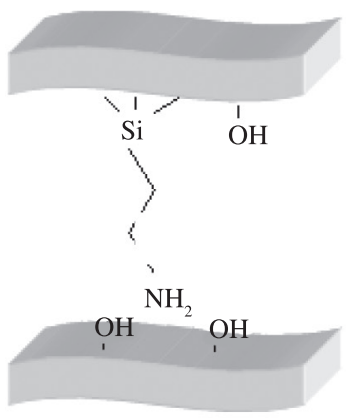

(b)

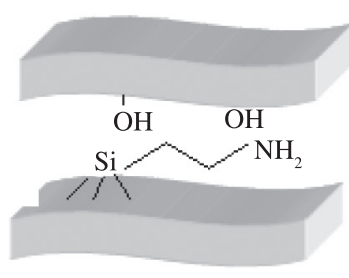

(c)

Figure 4. Proposed interaction of the amino centers attached to pendant organic chains with available acidic silanol groups of the lamella for the solid V1-N.

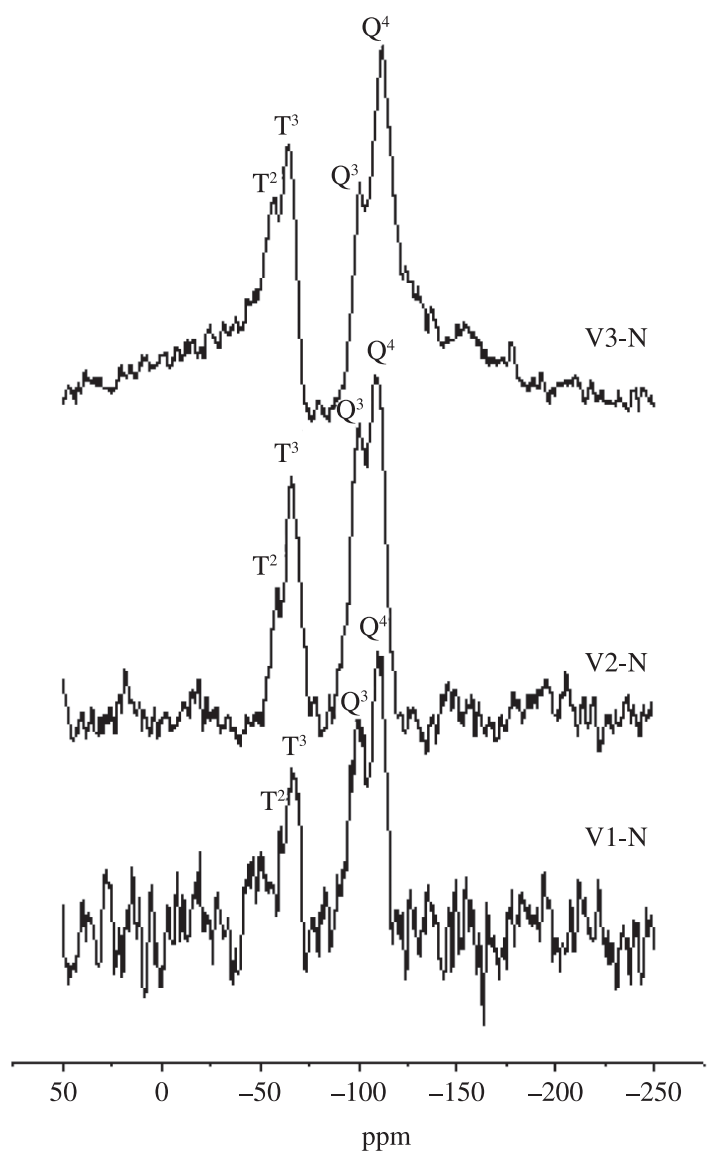

(a)

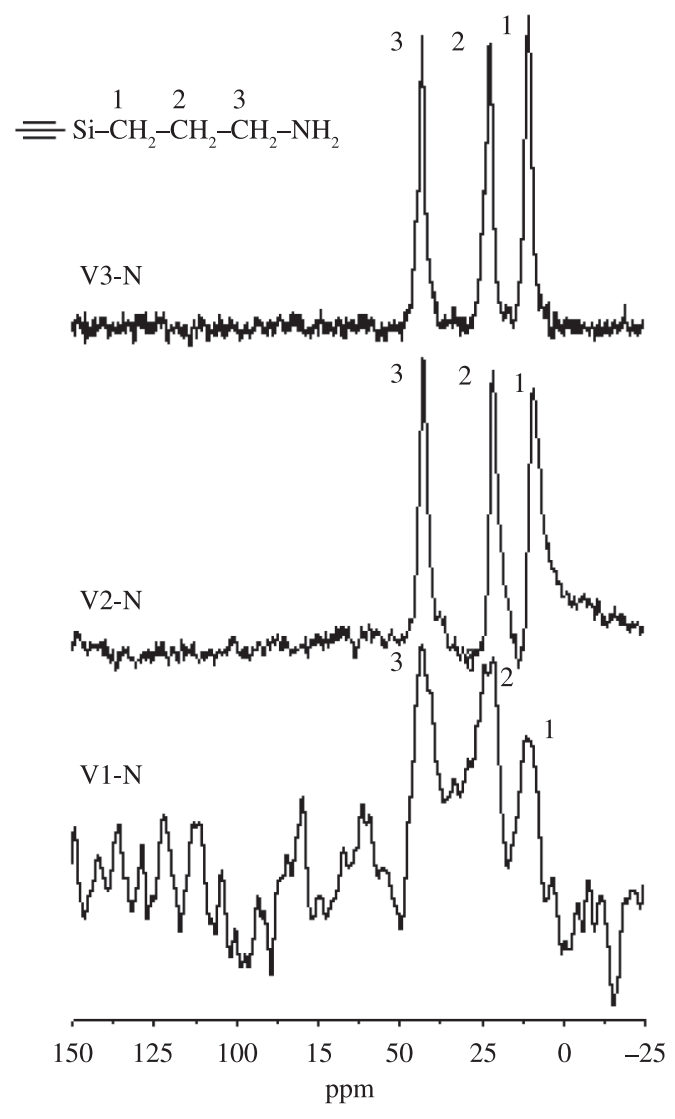

(b)

Figure 5. $\mathrm{Si}^{29}$ (a) and $\mathrm{C}^{13} \mathrm{NMR}$ spectra (b) for $\mathrm{Vm}-\mathrm{N}(\mathrm{m}=1,2,3)$ clays. 
structure, with the respective number in each spectrum. This combination of results demonstrates the successful grafting APS onto the clay surface.

\section{Conclusions}

The present investigation demonstrates that the grafting reaction between the trifunctional silylating agent and the layered silicates is influenced by the acidic pre-treatment. The immobilized silane molecules are distributed in a parallel-monolayer arrangement model in natural vermiculite $(\mathrm{V}-\mathrm{N})$ and perpendicularly in the leached vermiculite (V2-N). The different arrangements of silane molecules in the interlayer result in other $\mathrm{T}^{\mathrm{n}}$ units such as $\mathrm{T}^{1}\left[\mathrm{Si}(\mathrm{OSi})-\left(\mathrm{OR}^{\prime}\right)_{2} \mathrm{R}\right]$ and $\mathrm{T}^{2}\left[\mathrm{Si}(\mathrm{OSi})_{2}\left(\mathrm{OR}{ }^{\prime}\right) \mathrm{R}\right]$

\section{References}

1. Pereira KRO, Hanna RA, Vianna MMGR, Pinto CA, Rodrigues MGF and Valenzuela-Diaz FR. Brazilian organoclays as nanostructured sorbents of petroleum-derived hydrocarbons. Materials Research. 2005; 8(1):253-259. http://dx.doi. org/10.1590/S1516-14392005000100014

2. Lopes CW, Penha FG, Braga RM, Melo DMA, Pergher SBC and Petkowicz DI. Síntese e caracterização de argilas organofílicas contendo diferentes teores do surfactante catiônico brometo de hexadeciltrimetilamônio. Química Nova. 2011; 34(7):1152-1156. http://dx.doi.org/10.1590/ S0100-40422011000700009

3. Borah JS and Chaki TK. Exploring the simultaneous effect of organoclay and controlled peroxide curing on thermal stability of LLDPE/EMA blen. Thermochimica Acta. 2012; 529(10):45-50. http://dx.doi.org/10.1016/j.tca.2011.11.020

4. Conzatti L, Stagnaro P, Colucci G, Bongiovanni R, Priola A, Lostritto A et al. The clay mineral modifier as the key to steer the properties of rubber nanocomposites. Applied Clay Science. 2012; 61(1):14-21. http://dx.doi.org/10.1016/j. clay.2012.03.004

5. Bergaya F, Theng B and Lagaly G, editors. Handbook of Clay Science. Amsterdam: Elsevier; 2006. p. 1224.

6. Herrera NN, Letoffe JM, Putaux JL, David L and Elodie BL. Aqueous Dispersions of Silane-Functionalized Laponite Clay Platelets. A First Step Towards the Elaboration of Water-Based Polymer/Clay Nanocomposites. Langmuir. 2004; 20:1564-1571. http://dx.doi.org/10.1021/la0349267

7. Ha SR and Rhee KY. Effect of surface-modification of clay using 3-aminopropyltriethoxysilane on the wear behavior of clay/epoxy nanocomposites. Colloid Surface A. 2008; 322(1):15. http://dx.doi.org/10.1016/j.colsurfa.2008.03.007

8. Zhu L, Zhu R, Xu L and Ruan X. Influence of clay charge densities and surfactant loading amount on the microstructure of CTMA-montmorillonite hybrids. Colloid Surface A. 2007; 304:41-48. http://dx.doi.org/10.1016/j. colsurfa.2007.04.019

9. Yapar S. Physicochemical study of microwave-synthesized organoclays. Colloid Surface A. 2009; 345(1):75-81. http:// dx.doi.org/10.1016/j.colsurfa.2009.04.032

10. Steudel A, Batenburg LF, Fischer HR, Weidler PG and Emmerich $\mathrm{K}$. Alteration of non-swelling clay minerals and magadiite by acid activation. Applied Clay Science. 2009; 44:95-104. http:// dx.doi.org/10.1016/j.clay.2009.02.001 during condensation. Consequently, it leads to the different surface properties of the resulting products. It was also evident that the interlayer structure of the grafted products and the molecular environment of the grafted silane are strongly dependent on the prior clay chemical laboratory operations. The knowledge obtained on handling such types of inorganic material is of great significance for success in the synthetic procedure of polymer/layered silicate nanocomposites, to improve the properties and to provide useful extractable natural products.

\section{Acknowledgements}

The authors thank CNPq and CAPES for financial support and fellowships.

11. Okada K, Arimitsu N, KameshimaY, Nakajima A and MacKenzie KJD. Solid acidity of $2: 1$ type clay minerals activated by selective leaching. Applied Clay Science. 2006; 3:185-193. http://dx.doi.org/10.1016/j.clay.2005.10.014

12. Knöfel C, Descarpentries J, Benzaouia A, Zeleňák V, Mornet $\mathrm{S}$, Llewellyn PL et al. Functionalised micro-/mesoporous silica for the adsorption of carbon dioxide. Microporous Mesoporous Materials. 2007; 99:77-85. http://dx.doi.org/10.1016/j. micromeso.2006.09.018

13. Bertagnolli $\mathrm{C}$ and Carlos da Silva MG. Characterization of Brazilian Bentonite Organoclays as Sorbents of Petroleumderived Fuels. Materials Research. 2012; 15(2):253-259. http:// dx.doi.org/10.1590/S1516-14392012005000017

14. Almeida Neto AF, Vieira MGA and Carlos da Silva MG. $\mathrm{Cu}$ (II) Adsorption on Modified Bentonitic Clays: Different Isotherm Behaviors in Static and Dynamic Systems. Materials Research. 2012; 15(1):114-124. http://dx.doi.org/10.1590/ S1516-14392011005000089

15. Guimarães AMF, Ciminelli VST and Vasconcelo WL. Surface Modification of Synthetic Clay Aimed at Biomolecule Adsorption: Synthesis and Characterization. Materials Research. 2007; 10(1):37-41. http://dx.doi.org/10.1590/S151614392007000100009

16. Breen C and Watson R. Acid-activated organoclays: preparation, characterisation and catalytic activity of polycation-treated bentonites. Applied Clay Science. 1998; 12:479-494. http:// dx.doi.org/10.1016/S0169-1317(98)00006-4

17. Park K-W, Jung JH, Seo H-J and Kwon O-Y. Mesoporous silica-pillared kenyaite and magadiite as catalytic support for partial oxidation of methane. Microporous Mesoporous Materials. 2009; 121(1):219-225. http://dx.doi.org/10.1016/j. micromeso.2009.02.002

18. Xu G, Zhu X, Niu X, Liu S, Xie S, Li X et al. One-pot synthesis of high silica MCM-22 zeolites and their performances in catalytic cracking of 1-butene to propene. Microporous Mesoporous Materials. 2009; 118:44-51.

19. Maqueda C, Romero AS, Morilo E and Pérez-Rodríguez JL. Effect of grinding on the preparation of porous materials by acid-leached vermiculite. Journal of Physics and Chemistry of Solids. 2007; 68:1220-1224. http://dx.doi.org/10.1016/j. jpcs.2007.01.037

20. Harben PW. Industrial Minerals Handy Book, Industrial Minerals Division. London: Metal Bulletin PLC; 1995.

21. Lambert J-F and Poncelet G. Acidity in pillared clays: origin and catalytic manifestations. Topics Catal. 1997; 4:43-56. http://dx.doi.org/10.1023/A:1019175803068 
22. Lee SM and Tiwari D. Organo and inorgano-organo-modified clays in the remediation of aqueous solutions: An overview. Apllied Clay Science. 2012; 59-60:84-102. http://dx.doi. org/10.1016/j.clay.2012.02.006

23. Alves APM, Silva ALP, Silva OG, Fonseca MG, Arakaki LNH and Espinola JGP. Synthesis and characterization of hybrids derived from vermiculite chloropropyl and aliphatic diamines, Journal of Thermal Analysis and Calorimetry. 2007; 87(3):771-774. http://dx.doi.org/10.1007/s10973-006-7855-0

24. Temujin J, Okada K and MacKenzie KJD. Preparation of porous silica from vermiculite by selective leaching. Applied Clay Science. 2003; 22(4):187-195. http://dx.doi.org/10.1016/ S0169-1317(02)00158-8

25. Guillot M, Richard-Plouet $M$ and Vilminot S. Structural characterisations of a lamellar organic-inorganic nickel silicate obtained by hydrothermal synthesis from nickel acetate and (aminopropyl)triethoxysilane. Journal of Materials Chemistry. 2002; 12:851-857. http://dx.doi.org/10.1039/ b110101c

26. Brindley GW and Brown G, editors. Crystal Structures of Clay Minerals and their X-Ray Identification. London: Mineralogical Society; 1980.

27. Fonseca MG, Wanderley AF, Sousa RK, Arakaki LNH and Espinola JGP. Interaction of aliphatic diamines with vermiculite in aqueous solution. Applied Clay Science. 2006; 32(1-2):94-98. http://dx.doi.org/10.1016/j.clay.2005.10.013

28. He H, Duchet J, Galy J and Gerard J-F. The influence of cationic surfactant removal on the thermal stability of organoclays.
Journal of Colloid and Interface Science. 2005; 288(1):171-176. http://dx.doi.org/10.1016/j.jcis.2005.02.092

29. Del Rey-Perez-Caballero J and Poncelet G. Microporous 18A Al-pillared vermiculites: preparation and characterization. Microporous Mesoporous Materials. 2000; 37:313-327. http:// dx.doi.org/10.1016/S1387-1811(99)00274-7

30. Mackenzie KJD and Smith ME. Multinuclear Solid-State NMR of Inorganic Materials. Oxford: Pergamon Materials Series, Pergamon- Elsevier; 2002. p. 333-550.

31. Guo Y, Wang Y, Yang Q, Li G, Wang C, Cui Z et al. Preparation and characterization of magadiite grafted with an azobenzene derivative. Solid State Science. 2004; 6:1001-1006. http:// dx.doi.org/10.1016/j.solidstatesciences.2004.04.006

32. He H, Frost RL, Deng F, Zhu J, Wen X and Yuan P. Conformation of Surfactant Molecules in the Interlayer of Montmorillonite Studied by ${ }^{13} \mathrm{C}$ MAS NMR. Clays Clay Minerals. 2004; 52:350-356. http://dx.doi.org/10.1346/ CCMN.2004.0520310

33. Wang X, Lin KSK, Chan JCC, Cheng S. Direct Synthesis and catalytic applications of ordered large pore aminopropylfunctionalized SBA-15 mesoporous materials. Journal of Physical Chemistry B. 2005; 109:1763-1769. http://dx.doi. org/10.1021/jp045798d

34. Ek S, Iiskola EI, Niinistö L, Vittinen J, Pakkanen TT and Root AA. ${ }^{29} \mathrm{Si}$ and ${ }^{13} \mathrm{CCP} / \mathrm{MAS}$ NMR study on their surface species of gas-phase-deposited $\gamma$-aminopropylalkosilanes on heat-treated silica. Journal of Physical Chemistry B. 2004; 108:11454-11463. http://dx.doi.org/10.1021/jp048927z 